Article

\title{
Sensitivity of Multi-Source SAR Backscatter to Changes in Forest Aboveground Biomass
}

\author{
Wenli Huang ${ }^{1, *}$, Guoqing Sun ${ }^{1}$, Wenjian Ni ${ }^{2}$, Zhiyu Zhang ${ }^{2}$ and Ralph Dubayah ${ }^{1}$ \\ 1 Department of Geographical Sciences, University of Maryland, College Park, MD 20742, USA; \\ E-Mails: Guoqing.Sun@nasa.gov (G.S.); dubayah@umd.edu (R.D.)
}

2 State Key Laboratory of Remote Sensing Science (Jointly Sponsored by the Institute of Remote Sensing and Digital Earth, Chinese Academy of Sciences, and Beijing Normal University), Chinese Academy of Sciences, Beijing 100101, China; E-Mails: niwj@radi.ac.cn (W.N.); zhangzy@radi.ac.cn (Z.Z.)

* Author to whom correspondence should be addressed; E-Mail: wlhuang@umd.edu; Tel.: +1-301-405-3076; Fax: +1-301-314-9299.

Academic Editors: Conghe Song and Prasad S. Thenkabail

Received: 27 February 2015 / Accepted: 20 July 2015 / Published: 28 July 2015

\begin{abstract}
Accurate estimates of forest aboveground biomass (AGB) after anthropogenic disturbance could reduce uncertainties in the carbon budget of terrestrial ecosystems and provide critical information to policy makers. Yet, the loss of carbon due to forest disturbance and the gain from post-disturbance recovery have not been sufficiently assessed. In this study, a sensitivity analysis was first conducted to investigate: (1) the influence of incidence angle and soil moisture on Synthetic Aperture Radar (SAR) backscatter; (2) the feasibility of cross-image normalization between multi-temporal and multi-sensor SAR data; and (3) the possibility of applying normalized backscatter data to detect forest biomass changes. An empirical model was used to reduce incidence angle effects, followed by cross-image normalization procedure to lessen soil moisture effect. Changes in forest biomass at medium spatial resolution $(100 \mathrm{~m})$ were mapped using both spaceborne and airborne SAR data. Results indicate that (1) the effect of incidence angle on SAR backscatter could be reduced to less than $1 \mathrm{~dB}$ by the correction model for airborne SAR data; (2) over $50 \%$ of the changes in SAR backscatter due to soil moisture could be eliminated by the cross-image normalization procedure; and (3) forest biomass changes greater than $100 \mathrm{Mg} \cdot \mathrm{ha}^{-1}$ or above $50 \%$ of $150 \mathrm{Mg} \cdot \mathrm{ha}^{-1}$ are detectable using cross-normalized SAR data.
\end{abstract}


Keywords: forest aboveground biomass; SAR backscatter; formalization; incidence angle; PALSAR; UAVSAR; SIR-C/XSAR; AIRSAR

\section{Introduction}

The carbon budget of terrestrial ecosystems contains large uncertainties at both global and regional scales [1]. Aboveground biomass (AGB, hereafter biomass) stock from forest represents an important component of the global carbon cycle and related carbon policy [2]. Anthropogenic disturbance including deforestation and forest degradation due to management has led to significant changes in biomass and thus the carbon budget [3]. However, the loss of carbon due to deforestation and forest degradation, and the gain from post-disturbance recovery have not been sufficiently assessed. The use of active remote sensing techniques such as Synthetic Aperture Radar (SAR) is a promising approach for measuring and monitoring the spatial and temporal variation of forest carbon stock [3-5].

Imaging with SAR has advantages over optical imagery in its capacity to penetrate clouds, rain, smoke, and haze, which are known problems for optical sensors. The ability to penetrate the forest canopy makes it possible to retrieve the forest structure as a function of backscatter mechanisms [4]. Generally, studies have reported that SAR backscatter is more sensitive to canopy biomass (especially tree trunks) at longer wavelengths. Full polarimetric SAR (PolSAR) provides four combinations of transmitted and received polarizations: co-polarized bands $\mathrm{HH}$ (horizontal transmitted and horizontal received) and VV (vertical transmitted and vertical received), as well as cross-polarized bands HV (horizontal transmitted and vertical received) and $\mathrm{VH}$ (vertical transmitted and horizontal received). Longer SAR wavelengths such as P- $(30-100 \mathrm{~cm})$ and L- $(15-30 \mathrm{~cm})$ bands penetrate farther into the forest canopy and capture more vertical structure than C- $(4.8-7.7 \mathrm{~cm})$ and $\mathrm{X}-(2.8-5.2 \mathrm{~cm})$ bands, while $\mathrm{HV}$ backscatters from dual polarization (e.g., $\mathrm{HH}$ and $\mathrm{HV}$ ) or full polarization (i.e., $\mathrm{HH}, \mathrm{VV}$, HV, and $\mathrm{VH})$ are more sensitive to woody biomass.

A series of studies suggested that a widely applicable relationship exists between biomass and backscatter from L-band SAR for woody vegetation with lower levels of biomass $\left(\leq 150 \mathrm{Mg} \cdot \mathrm{ha}^{-1}\right)$ in tropical [6-8], temperate and boreal biomes [9-13]. Both airborne and spaceborne systems were involved in these studies, including airborne instruments such as AIRborne SAR (AIRSAR) and the Uninhabited Aerial Vehicle SAR (UAVSAR) developed by the National Aeronautics and Space Administration (NASA), Experimental-SAR (ESAR) operated by the German Aerospace Center (DLR), as well as spaceborne instruments such as the first Earth-orbiting satellite SEASAT, Spaceborne Imaging Radar-C and X-B and SAR (SIR-C/XSAR), Japanese Earth Resources Satellite 1 (JERS-1), and Phased Array type L-band SAR (PALSAR) on board the Advanced Land Observing Satellite (ALOS) operated by the Japan Aerospace Exploration Agency (JAXA). Ranson et al. [10] investigated the use of multi-frequency, multi-polarization and multi-season image data from SIR-C/XSAR to map forest cover type and estimate aboveground biomass for a Boreal Ecosystem-Atmosphere Study (BOREAS) site in Saskatchewan, Canada. Santos et al. [6] utilized the L-HH channel of JERS-1 data in tropical forest-savanna contact zones, and found that the logarithmic and sigmoid functions were adequate to explain the SAR backscatter as a function of forest biomass. Collins et al. [7] indicated that the L-HV channel of polarimetric backscatter 
intensity from AIRSAR was best suited $\left(\mathrm{R}^{2}=0.92\right)$ for modeling biomass (both above-ground and below-ground) of the tropical savannahs in North Australia. Mitchard et al. [8] examined the relationships between field-measured biomass at four study sites in Cameroon, Uganda and Mozambique and L-band HV data from ALOS/PALSAR, and found that biomass estimates based on these relationships were highly significant and similar among sites. Sandberg et al. [12] explored the relationship between SAR backscatter from E-SAR data and forest biomass in southern Sweden, and found that for L-band data the best results were obtained from HV-polarized backscatter. Robinson et al. [13] studied the variation in field estimated biomass at different scales $(0.0625,0.25,0.5$, and $1.0 \mathrm{ha})$ in a temperate to boreal transitional region (Howland, ME), and found that the cross-polarized HV had the highest sensitivity to field estimated biomass $\left(\mathrm{R}^{2}=0.68\right)$.

Data from L-band PolSAR have been applied especially to monitor forest disturbance and post-disturbance recovery [14-16]. Luckman et al. [14] compared biomass estimates from spaceborne SAR instruments such as SIR-C and JERS-1 and concluded that L-band SAR data were suitable for detecting regeneration in tropical regions. Baltzer et al. [15] employed multi-sensor L-band SAR (i.e., spaceborne SEASAT and JERS-1 SAR) to map regrowth of a conifer plantation in the Thetford forest, UK. Rowland et al. [16] used AIRSAR and ESAR data to monitor forest regrowth from 1991 to 2010. Santoro et al. [17] utilized airborne and space borne data such as PALSAR to detect clearcutting of a boreal forest from July 2007 to October 2008 and found a temporal consistency in the time series of L-HV backscatter measurements and developed a detection algorithm for clear-cut areas.

Nevertheless, a number of important factors can affect the relationship between radar backscatter and forest biomass, including changes in forest structure [11], radar incidence angle (IA) [18,19] and look direction [20], surface and environmental conditions (soil moisture and roughness) [21-23], trunk dielectric properties [24] and saturation [4,25,26]. Backscatter from vegetated areas depends on a combination of canopy structure and underlying surface conditions [27]. The former is related to water content of the vegetation, while the latter is linked to soil moisture (SM) changes. Both (vegetation and soil) are affected by environmental factors such as temperature and moisture that will affect the dielectric constants of the target. These effects (i.e., temperature and moisture) need to be removed before any further analysis of changes caused by forest disturbances. Ranson and Sun [27] reported up to a $7 \mathrm{~dB}$ change in backscatter coefficient between frozen and non-frozen conditions and suggested multi-year comparisons under similar temperature conditions should be made such during in the summer growing season. In addition, saturation in SAR backscatter varies among different bands. Dobson et al. [25] indicated biomass saturation levels of $\sim 200 \mathrm{Mg} \cdot \mathrm{ha}^{-1}$ and $\sim 100 \mathrm{Mg} \cdot \mathrm{ha}^{-1}$ for P-band and L-band polarimetric SAR (PolSAR), respectively. Imhoff [28] reported that the radar signal saturation was $\sim 100 \mathrm{Mg} \cdot \mathrm{ha}^{-1}$ for the P-band, $\sim 40 \mathrm{Mg} \cdot \mathrm{ha}^{-1}$ for the L-band, and $\sim 20 \mathrm{Mg} \cdot \mathrm{ha}^{-1}$ for the C-band by comparing SAR backscatter and forest biomass relationships over a tropical broadleaf evergreen forest in Hawaii and coniferous forest stands in North America and Europe. Ranson and Sun [26] indicated that SAR backscatter from AIRSAR and SIR-C could provide estimates of biomass up to $\sim 150 \mathrm{Mg} \cdot \mathrm{ha}^{-1}$ with an average of $97 \mathrm{Mg} \cdot \mathrm{ha}^{-1}$. Lucas et al. [23] studied the relationship between PALSAR data and biomass in Australia, and concluded that PALSAR data acquired when surface moisture and rainfall are minimal allow better estimation of the biomass of woody vegetation and that retrieval algorithms ideally need to consider differences in surface moisture conditions and vegetation structure. 
However, few studies have focused on analyzing the sensitivity of multi-source SAR backscatter to changes in forest biomass after forest disturbance because of issues such as limited SAR data acquisition over time, as well as effects from incidence angles, and surface conditions. Zink et al. [29] conducted a comparative study of different airborne SAR data from AIRSAR and ESAR, and demonstrated that cross-calibration is feasible for radar data obtained through stable systems under similar conditions. Ustin et al. [30] indicated that changes in biomass during the early stages of secondary succession could be monitored by L-band airborne SAR data for two datasets with an interval of five years. Sandberg et al. [31] estimated biomass change in a hemi-boreal forest from 2007 to 2010 using airborne P-band SAR data, and concluded that growth and thinning in a forest can be measured with 64 equivalent number of looks (ENL) in SAR imagery and a 50\% change in biomass.

This paper will describe our analysis of the sensitivity of multi-temporal and multi-sensor SAR signatures to changes in forest biomass. The objectives were to investigate: (1) a procedure to reduce the distortion in SAR backscatter caused by incidence angle and soil moisture; (2) the feasibility of cross-image calibration between multi-temporal and multi-sensor SAR data; and (3) the possibility of applying normalized backscatter to detect changes in biomass due to forest disturbance and post-disturbance recovery. The paper is organized as follows. Section 2 describes the study area and data. Section 3 explores the factors that influence changes in SAR backscatter. A cross-image normalization method is proposed to reduce the offset between images acquired from multi-source SAR data. In Section 4, the performance of our correction is evaluated and applied to selected stands after forest disturbance. A biomass-backscatter regression model is developed from field measurements, and applied to map changes in forest biomass in the study area. Lastly, in Sections 5 and 6, the significance and limitations of the results are discussed and conclusions are drawn.

\section{Study Area and Data}

The study site Howland Research Forest (HF) is located in the Northern Experimental Forest $\left(45^{\circ} 08^{\prime} \mathrm{N}-45^{\circ} 14^{\prime} \mathrm{N}, 68^{\circ} 42^{\prime} \mathrm{W}-68^{\circ} 45^{\prime} \mathrm{W}\right)$, Penobscot County, Maine, USA (Figure 1). The dominant species include Abies balsamea (balsam fir), Picea rubens (red spruce), Tsuga canadensis (hemlock), Populus tremuloides (quaking aspen), Betula papyrifera (paper birch), and Acer rubrum (red maple). The HF has been owned and actively managed by International Paper® (IP), over the last three decades, including clear-cutting during the 1980s, strip-cutting during the 1990s, and selective-cutting after 2000. The region has a relative flat topography with gently rolling hills.

The HF site is located within the original area of the NASA Forest Ecosystem Dynamics (FED) Multi-sensor Aircraft Campaign (MAC) carried out during the 1990s. Therefore, abundant ground measurements and remotely sensed datasets were available. In addition, independent field measurements were collected from 1992-2009.

\subsection{Field Campaign}

Forty-nine forest stands (FIA style plot) were measured in April 1992 during the MAC campaign [9]. Trunk diameter at breast height $(\mathrm{DBH})$ and species were recorded. For each stand, an identifiable point on the AIRSAR image near or on a road was selected as a starting point, and the bearing and distance from this point to the center of the sample stand were measured. From the center point of the stand, three $50.3 \mathrm{~m}^{2}$ 
plots were located $15 \mathrm{~m}$ to the north, southeast, and southwest from the center. The DBH and species of every tree with $\mathrm{DBH}>3 \mathrm{~cm}$ were recorded for each plot.

Twenty-four 1.0 ha plots (hectare plot, $200 \mathrm{~m} \times 50 \mathrm{~m}$ ) with a biomass ranging from 1 to $278.9 \mathrm{Mg} \cdot \mathrm{ha}^{-1}$ were established in 2009 during the NASA/JPL UAVSAR field campaign [32]. The long edges of these plots were oriented in the range direction of the UAVSAR flight lines. The layout of these plots is illustrated in Figure 1b, where each plot consists of sixteen 0.25 ha (quarter hectare plot, $25 \mathrm{~m} \times 25 \mathrm{~m}$ ) subplots. The $\mathrm{DBH}$, species of every tree with a $\mathrm{DBH} \geq 10 \mathrm{~cm}$, top height, height of crown base, and crown width of the three highest trees in each subplot were recorded. A census of stems below the established size threshold (DBH $<10 \mathrm{~cm}$ ) and height of $\geq 1.3 \mathrm{~m}$ were sampled within a $2 \mathrm{~m}$ transect along the center of each rectangular plot. The number of stems falling into four diameter categories (i.e., 0-2 cm, 2-5 cm, 5-8 cm, and 8-10 cm) was counted and used as a representative sample of all small stems in the plot. Biomass values at the study site range from $0.3-361.4 \mathrm{Mg} \cdot \mathrm{ha}^{-1}$ for 0.25 ha plots, 0.6-316 Mg $\mathrm{ha}^{-1}$ for 0.5 ha plots, and from $1.0-278.9 \mathrm{Mg} \cdot \mathrm{ha}^{-1}$ for hectare plots. Trees with a DBH greater than $10 \mathrm{~cm}$ were directly recorded and trees with dbh below $10 \mathrm{~cm}$ were sampled. Individual tree biomass was calculated with allometric equations, and plot-level biomass was summarized then converted to biomass density (as $\mathrm{Mg} \cdot \mathrm{ha}^{-1}$ ). The diameter-based allometric equations used for large stems $(\mathrm{DBH} \geq 10 \mathrm{~cm})$ and small stems $(\mathrm{DBH}<10 \mathrm{~cm})$ were derived from the USDA comprehensive report on North American forests [33]. Biomass of large stems was calculated by corresponding generalized species-specific allometric equations. Biomass of the small stems was calculated by mixed hardwoods equations using the midpoint of the diameter class (i.e., $1.0 \mathrm{~cm}, 2.5 \mathrm{~cm}, 6.5 \mathrm{~cm}$, and $9.0 \mathrm{~cm}$ ) as the DBH, multiplied by the number of stems in each category. Biomass was first calculated for each stem, and then total biomass was aggregated from subplot to plot levels.

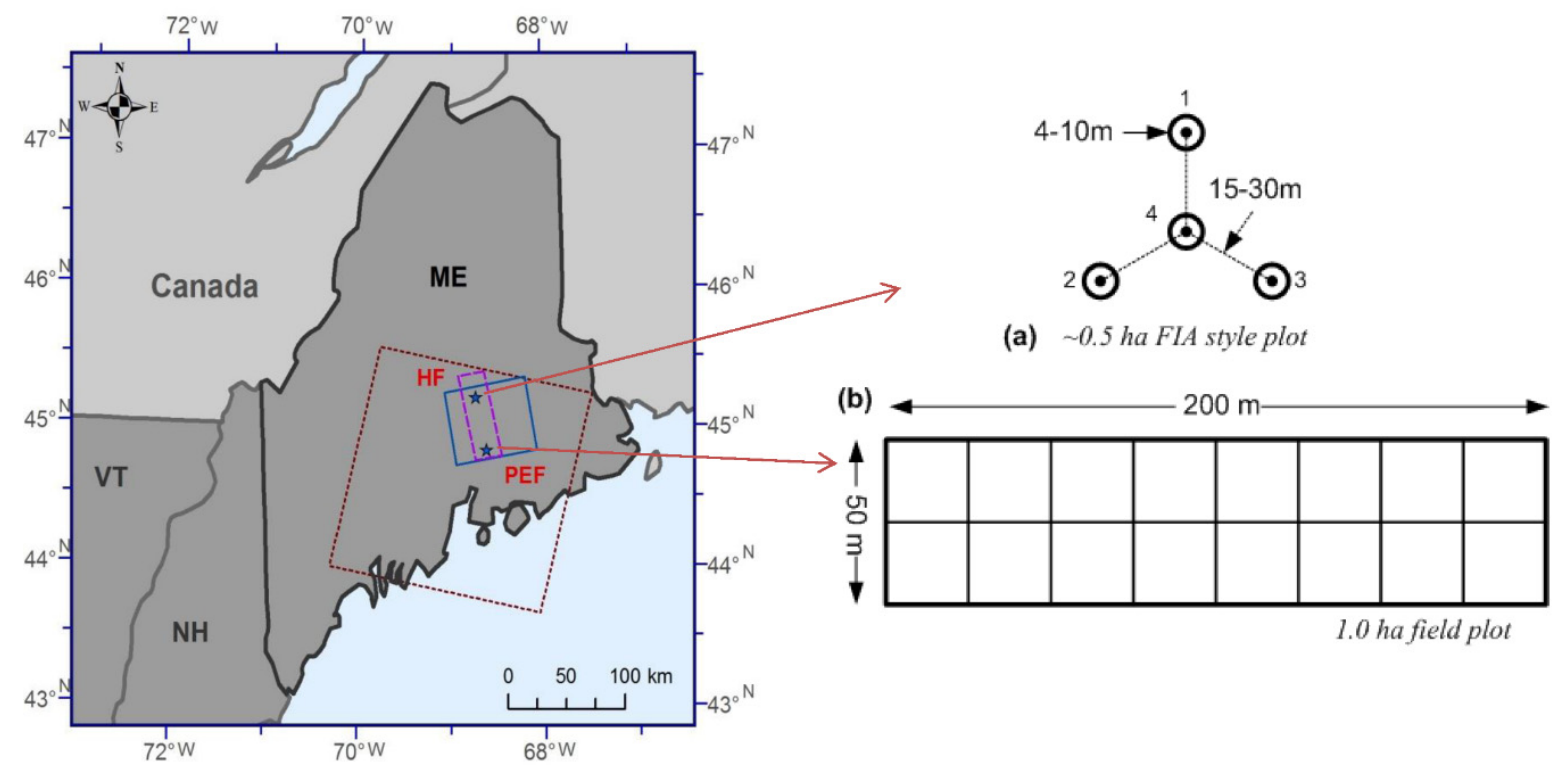

Figure 1. Map of study sites, and coverage of Landsat ETM+ scene (red dashed line, p011/r029), ALOS PALSAR FBD scene (blue solid line), and PLR scene (purple dashed line). (a) FIA style plot, and (b) 1.0 ha field plot. 


\subsection{SAR Data}

All SAR data used in this study were collected from middle April to early October and by systems operating at the L-band (23.6 cm wavelength or $1.3 \mathrm{GHz}$ frequency). Specifically, quad-polarization (HH, VV, HV, and VH) L-band SAR data were collected in 1994 from AIRSAR and SIR-C/X-SAR data collected in April and October 1994. The ALOS was launched in 2006 with a 46-day repeat cycle, and PALSAR data were collected for the study area from 2007-2010 with fine beam dual mode (FDB; HH and HV).

Meanwhile, UAVSAR data were collected for the study area in August 2009, with looking angle ranges of $20^{\circ}-60^{\circ}$. Details of SAR data selected for this study are listed in Table 1, including acquisition date, pixel size, center incidence angle, and environmental conditions such as temperature and precipitation.

Table 1. SAR data selected for sensitivity analysis. *Pixel size for the multi-looked ground-projected product. \#incidence angles are at scene center; for technical specifications see https://www.asf.alaska.edu/sar-data.

\begin{tabular}{|c|c|c|c|c|c|c|c|c|}
\hline \multirow{3}{*}{ Sensor } & \multirow{3}{*}{ Scene ID } & \multirow{3}{*}{$\begin{array}{c}\text { Acquisition } \\
\text { Date }\end{array}$} & \multirow{3}{*}{ 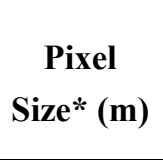 } & \multirow{3}{*}{$\begin{array}{l}\text { Incidence } \\
\operatorname{Angle}^{\#}\left(^{\circ}\right)\end{array}$} & \multicolumn{4}{|c|}{ Environmental Conditions } \\
\hline & & & & & \multirow{2}{*}{$\begin{array}{c}\text { Temperature } \\
\left({ }^{\circ} \mathrm{C}\right)\end{array}$} & \multicolumn{3}{|c|}{ Precipitation (mm) } \\
\hline & & & & & & 3 Day & 7 Day & 14 Day \\
\hline SIR-C/XSAR & PR12331 & 04/13/1994 & 12.5 & 31.7 & $\mathrm{~T} \sim 5.5^{\circ} \mathrm{C}$ & 17.3 & 42.1 & 50.9 \\
\hline SIR-C/XSAR & PR47494 & 10/04/1994 & 12.5 & 31.7 & $\mathrm{~T} \sim 10.1^{\circ} \mathrm{C}$ & 0 & 0.2 & 76 \\
\hline AIRSAR & l & 09/02/1989 & 10 & 35.0 & $\mathrm{~T} \sim 10.1^{\circ} \mathrm{C}$ & 16.8 & 18.6 & 27.6 \\
\hline AIRSAR & CM6221 & 10/07/1994 & 10 & 35.0 & $\mathrm{~T} \sim 10.1^{\circ} \mathrm{C}$ & 0 & 0.2 & 76 \\
\hline UAVSAR & 16702_09054_016 & 08/05/2009 & 6 & 48.0 & $\mathrm{~T} \sim 21.6^{\circ} \mathrm{C}$ & 11.5 & 49.6 & 94.4 \\
\hline PALSAR/FBD & ALPSRP191680890 & 08/30/2009 & 20 & 34.3 & $\mathrm{~T} \sim 14.8^{\circ} \mathrm{C}$ & 20.4 & 32 & 34.2 \\
\hline
\end{tabular}

\subsection{Auxiliary Data}

Local forest management maps, Landsat derived disturbance maps, and climate data were prepared as referenced datasets for the study site. Forest management maps were digitized and composited from scanned American Forest Management (AFM) maps rectified to road maps and satellite images with UTM/WGS84 map projection for the study site from 1980 to 2011. The products of a yearly forest disturbance map from Landsat time series stack vegetation change tracker (LTSS-VCT) [34] were prepared for the study area (see details in [32]).

In addition, with an AmeriFlux tower located in the HF study site, various climate data were collected from 1987, including daily air temperature, total precipitation, wind speed, etc. The soil near the AmeriFlux tower consists with 50.35\% sand, 33.75\% silt, and $15.9 \%$ clay. From autumn of 1999, soil moisture, temperature and salinity were collected by five Hydra-Vitel probes and thermistors buried at depths of $\sim 5 \mathrm{~cm}, 10 \mathrm{~cm}, 20 \mathrm{~cm}, 50 \mathrm{~cm}$, and $100 \mathrm{~cm}$.

\section{Methodology}

Sensitivity analysis in this study includes three steps: incidence angle effect reduction, soil moisture effect reduction, and determination of sensitivity to forest biomass (Figure 2). First, a theoretical model and field measurements are employed to illustrate the relationship between SAR backscatter and forest biomass. Then, an empirical model is applied to reduce incidence angle effects on SAR backscatter. The 
influence of soil moisture on SAR backscatter is analyzed through in-situ soil moisture and field biomass studies. A cross-image normalization procedure is used to lessen the environmental effect on SAR backscatters. Lastly, the sensitivity of SAR backscatter to biomass is determined using normalized SAR data and field measurements.

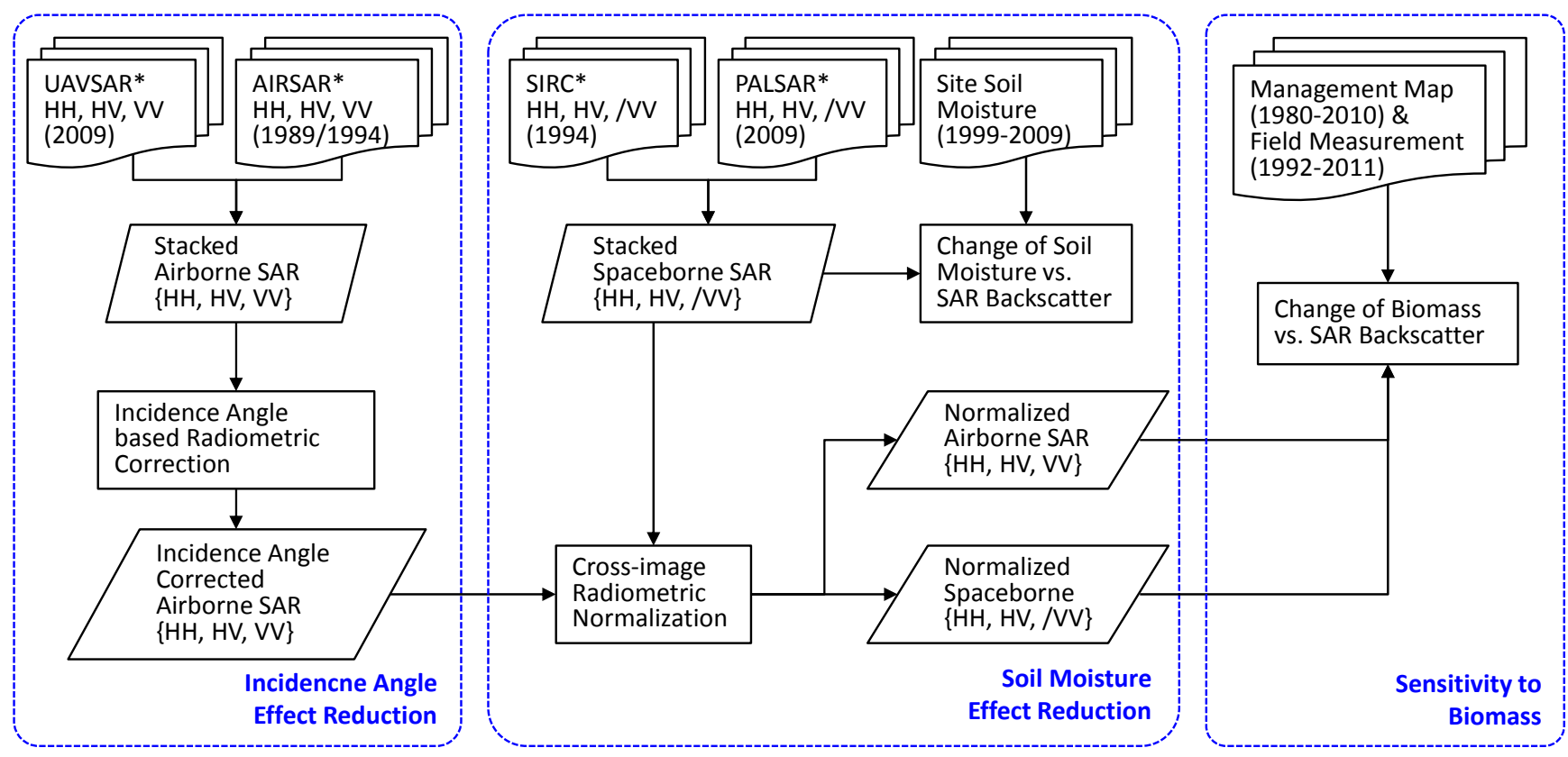

Figure 2. Flowchart of SAR data processing and sensitivity analysis.

\subsection{Sensitivity of SAR Backscatter to Biomass}

We employed a theoretical model to show the sensitivity of L-band SAR backscatter to forest biomass. ZELIG [35] is an individual tree-based forest gap model with the ability to simulate a forest ecosystem with complex species composition over a long period. Driven by temperature and precipitation data, as well as growth and environmental response parameters of each tree species and soil characteristics [36], the model was parameterized for the Howland Forest [37]. The outputs of the ZELIG model are forest stand parameters, including biomass density, forest height and leaf area index (LAI), and the size of each tree. Then, a radar model that simulated L-band radar backscatter of PolSAR data was implemented based on the output of the ZELIG model [18,38]. A look-up table (LUT) was generated from the physical-based forest backscatter model and was used in this study.

Based on model simulations as well as field measurements, the relationship between SAR backscatter and forest biomass is strong (Figure 3). However, the SAR backscatter has a wider dynamic range when the level of biomass density is high. The simulated SAR attributes for co-polarization $(\mathrm{HH})$ and crosspolarization (HV) were plotted as a function of simulated forest biomass from the look-up table, where different soil types reflected differences in the hydrological condition related to soil moisture and ground roughness [36,38]. The SAR backscatter data from airborne (UAVSAR) and spaceborne observations (PALSAR) were plotted as a function of field measured biomass (Figure 3, in blue circles). The figure shows that when biomass increases from 0 to $50 \mathrm{Mg} \cdot \mathrm{ha}^{-1}$, the backscatter ranges from $-20 \mathrm{~dB}$ to $-13 \mathrm{~dB}$ $(\sim 7 \mathrm{~dB})$ at $\mathrm{HV}$ polarization, and from $-14 \mathrm{~dB}$ to $-9 \mathrm{~dB}$ at $\mathrm{HH}$ polarization $(\sim 5 \mathrm{~dB})$. This is consistent with conclusions in the aforementioned literature that $\mathrm{HV}$ is more sensitive to forest disturbance than 
$\mathrm{HH}$; and that $\mathrm{HV}$ is sensitive to structures of post-disturbance tree regrowth, while $\mathrm{HH}$ is more sensitive to moisture content of the soils.
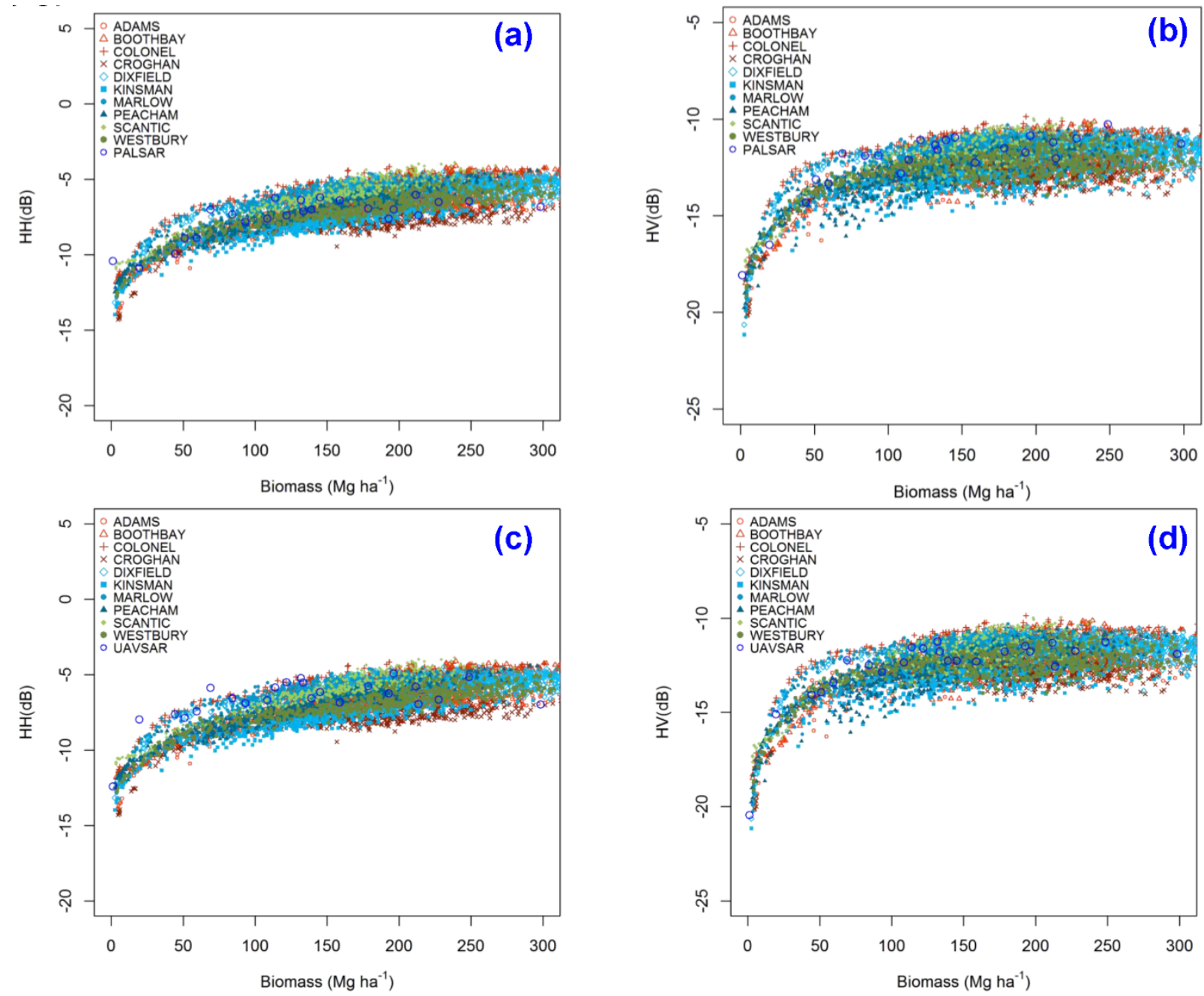

Figure 3. SAR backscatter as a function of forest aboveground biomass from model simulation and remote sensing observations. Simulations from ZELIG are plotted with (a) PALSAR HH, (b) PALSAR HV, (c) UAVSAR HH, and (d) UAVSAR HV. ADAMS-WESTBURY are the different types of soil based on drainage and taxonomic classification [36].

The above analysis indicates that changes in forest biomass after disturbance are detectable from SAR backscatter. However, many factors other than the change in forest structure and biomass, such as radar incidence angle and surface conditions, also affect the radar backscattering. The influence of these factors will be discussed in the following sections.

\subsection{Incidence-Angle-Based Correction for Airborne SAR Backscatter}

Numerous studies have indicated that incidence angle variations lead to changes in backscatter $[18,19]$, and that a model-based correction was effective in reducing IA influence on SAR backscatters [39,40]. Thus, for airborne SAR data (AIRSAR and UAVSAR), two sets of empirical models incidence angle correction were developed: 
$\mathrm{HH}$ and $\mathrm{HV}$ polarization:

$$
\sigma_{\text {raw }}^{o}=\sigma_{c}^{o} \cdot\left(\cos \theta / \cos \theta_{c}\right)^{n}
$$

VV polarization:

$$
\sigma_{\text {raw }}^{o}=\sigma_{c}^{o} \cdot\left(\theta / \theta_{c}\right)^{n}
$$

where $\sigma_{\text {raw }}^{o}$ is the raw backscatter before correction, $\theta_{c}$ is the radar incidence angle at the center of the image, $\theta$ is the local incidence angle, and $n$ is the power exponent coefficient with a range of $[1,2]$ determined by target attributes. The local incidence angle is defined as the angle between the radar line-of-sight and the local vertical with respect to the geoid. If topography is gentle (i.e., slope near zero), then local incidence angle can be assumed equal to incidence angle.

Then, the correction models are applied to all pixels:

$\mathrm{HH}$ and HV polarization:

$$
\sigma_{\text {corr }}^{o}=\sigma_{\text {raw }}^{o} \cdot\left(\cos \theta_{c} / \cos \theta\right)^{n}
$$

VV polarization:

$$
\sigma_{\text {corr }}^{o}=\sigma_{\text {raw }}^{o} \cdot\left(\theta_{\mathrm{c}} / \theta\right)^{n}
$$

where $\sigma_{\text {corr }}^{o}$ is the corrected radar backscatter.

\subsection{Sensitivity of SAR Backscatter to Soil Moisture and Cross-Image Normalization}

To study the effect of surface environments such as soil moisture (SM) on changes in SAR backscatter, the relationship between SAR signatures and soil moisture for the period of 2007-2010 over the selected stands was analyzed. Based on the forest management map, SAR signatures near the AmeriFlux tower ( $\mathrm{S}$, near-mature forest with biomass $>200 \mathrm{Mg} \cdot \mathrm{ha}^{-1}$ ) and near the non-forested area (S2, clear-cut with biomass $<10 \mathrm{Mg} \cdot \mathrm{ha}^{-1}$ ) were extracted from PALSAR collected during the growth season (May to October in 2009). The relationship between SAR signatures and soil moisture is analyzed for the period of 2007-2010 (Figure 4).

A conceptual diagram of the cross-image normalization is shown in Figure 4. The existence of radar "saturation" and different mechanisms related to soil and canopy vegetation were utilized to conduct the cross-image normalization for multi-temporal and multi-sensor SAR data. Model simulations [38] have indicated that SAR backscatter from soil is stronger than that from canopy in low biomass area (i.e., non-forested areas), but weaker in high biomass areas (i.e., near-mature forest). The objective of the normalization was to produce SAR signatures, acquired from different times and/or by different sensors, with similar patterns with regard to their backscatter-biomass relationship. 


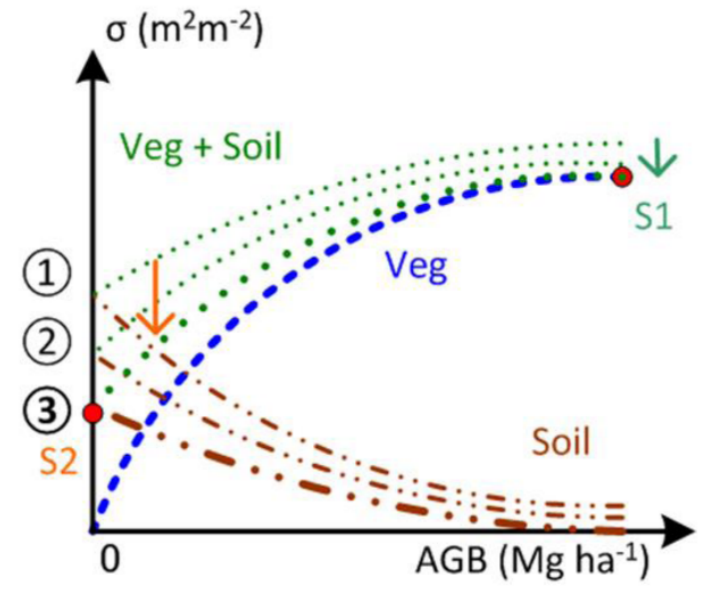

(Values are not to scale)

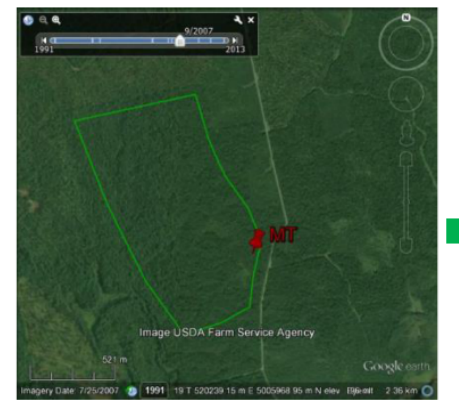

S1: saturation point (near mature forest) $\left(\mathrm{AGB}>200 \mathrm{Mg} \mathrm{ha}^{-1}\right.$ )

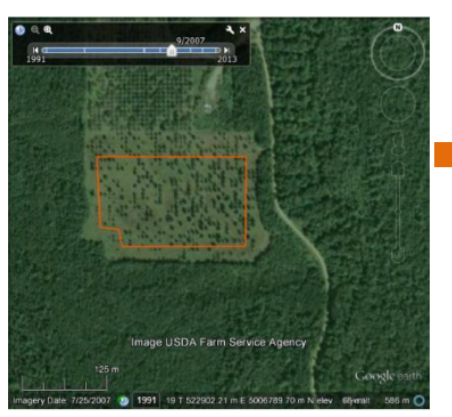

S2: low biomass (non-forest) $\left(\mathrm{AGB}<10 \mathrm{Mg} \mathrm{ha}^{-1}\right.$ )

Figure 4. Conceptual diagram of cross-image normalization. Figure units are power domain $\left(\mathrm{m}^{2} \cdot \mathrm{m}^{-2}\right)$ for backscatter $(\sigma)$, and density per hectare $\left(\mathrm{Mg} \cdot \mathrm{ha}^{-1}\right)$ for biomass; $\mathrm{S} 1$ is the saturation point in a near-mature forest; $\mathrm{S} 2$ is the maximum soil effect point in a non-forested area. Dashed blue line (Veg) is the fitted backscatter versus biomass received from vegetation canopy without soil influences in theory; Brown dashed and dotted lines are backscatter from soil surfaces. Green dotted lines are backscatter from vegetation canopy plus soil. (1)-3 denotes backscatter from data with different surface and soil moisture conditions.

The following two-step normalization was developed for both airborne and spaceborne SAR data. First, the one-point normalization makes use of the saturation point at higher levels of biomass (near-mature forest). The first step of the normalization can be expressed as:

$$
\sigma_{o}^{o}=\left(\sigma_{S 1 t}^{o} / \sigma_{S 1 o}^{o}\right) \cdot \sigma_{o}^{o}
$$

where $\sigma_{o}^{o}$ (sigma naught) is the original SAR backscatter before normalization. Both $\sigma_{S 1 t}^{o}$ and $\sigma_{S 1 o}^{o}$ are the SAR backscatter of a near-mature forest (S1) from the target (S1t) or reference image and the original image (S1o) that need to be normalized. The variables $\sigma_{S 2 t}^{o}$ and $\sigma_{S 2 o}^{O}$ are the SAR backscatter of the non-forested area (S2) from the target (S2t) or reference image and the image (S2o) that need to be normalized.

Then, the two-point normalization is applied to reduce the environmental effect of the soil component by subtracting it from the total signature. Normalized SAR backscatter after the second step of normalization $\left(\sigma_{o}^{\prime \prime O}\right)$ can be expressed as:

$$
\begin{aligned}
& \sigma_{o}^{\prime \prime o}=\sigma_{o}^{o}+\Delta \sigma^{o} \\
& \Delta \sigma^{o}=a \cdot \sigma_{o}^{o}+b
\end{aligned}
$$

where $\Delta \sigma^{o}$ is the difference between SAR backscatter at two different soil moisture conditions, and the coefficients $a$ and $b$ are derived from linear fitting of the data: 


$$
\begin{aligned}
& a=\left(\Delta \sigma_{S 1}-\Delta \sigma_{S 2}\right) /\left(\sigma_{S 1 o}^{\prime}-\sigma_{S 2 o}^{\prime}\right) \\
& b=\Delta \sigma_{S 1}-\left(\Delta \sigma_{S 1}-\Delta \sigma_{S 2}\right) /\left(\sigma_{S 1 o}^{\prime}-\sigma_{S 2 o}^{\prime}\right) \cdot \sigma_{S 1 o}^{\prime} \\
& \Delta \sigma_{S 1}=\sigma_{S 1 t}^{\prime}-\sigma_{S 1 o}^{\prime}, \Delta \sigma_{S 2}=\sigma_{S 2 t}^{\prime}-\sigma_{S 2 o}^{\prime}
\end{aligned}
$$

where $\sigma_{\mathrm{S} 1 \mathrm{t}}^{\prime}$ and $\sigma_{S 10}^{\prime}$ are the target and the original SAR backscatter, respectively, of mature forest (S1) from Equation (3). The variables $\sigma_{S 2 t}^{\prime}$ and $\sigma_{S 2 o}^{\prime}$ are the target and the original SAR backscatter of the non-forested area (S2) from Equation (3). Finally, $\Delta \sigma_{S 1}$ and $\Delta \sigma_{S 2}$ are the differences between SAR backscatter of the near-mature forest and the non-forested area under two different soil moisture conditions.

Stands with select-cut and clear-cut trees were selected with assistance from the forest management map (Figure 5) to test the proposed normalization algorithm, and to analyze the sensitivity of normalized changes in backscatter to forest biomass over time. Figure 5a shows the selected plots on the AIRSAR image (7 October 1994). Figure 5b shows the forest management map of logging activities from 1984 to 2011, where patches with different colors denote types and years of the disturbance. To make the management map comparable to the SAR images, the disturbances were reclassified into plantation before 1994 (1984-1993), plantation after 1994 (1994-1995), natural regrowth after prior clear-cut, select-cut and strip-cut events (1984-1993), and recent select-cut (1994-1908).

\section{(a)}

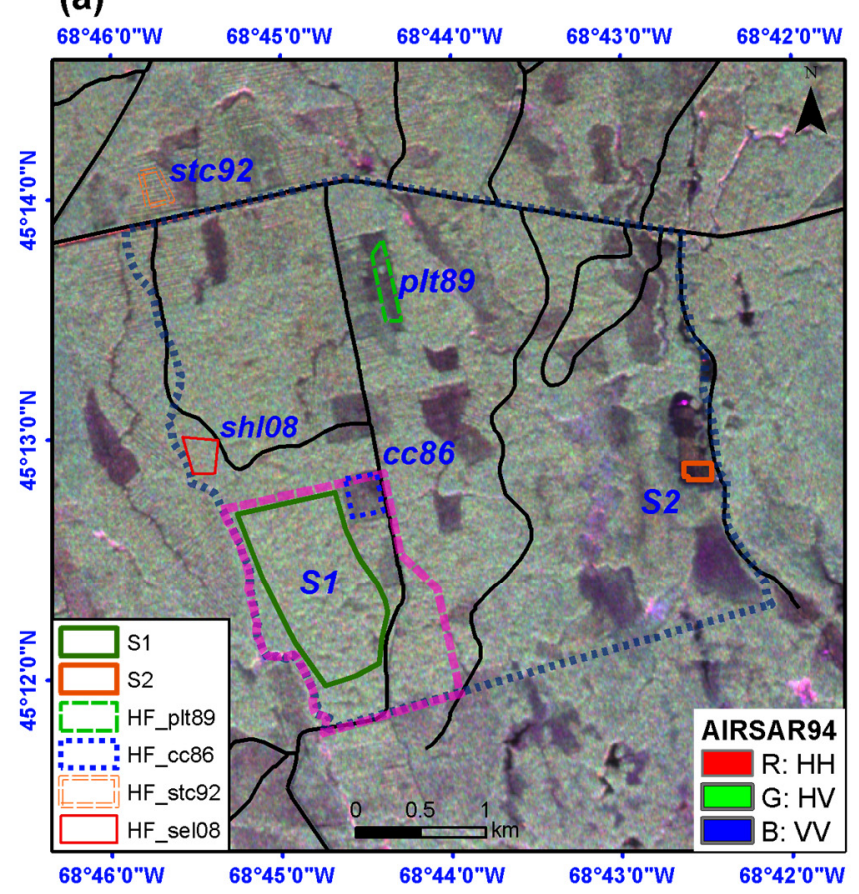

(b)

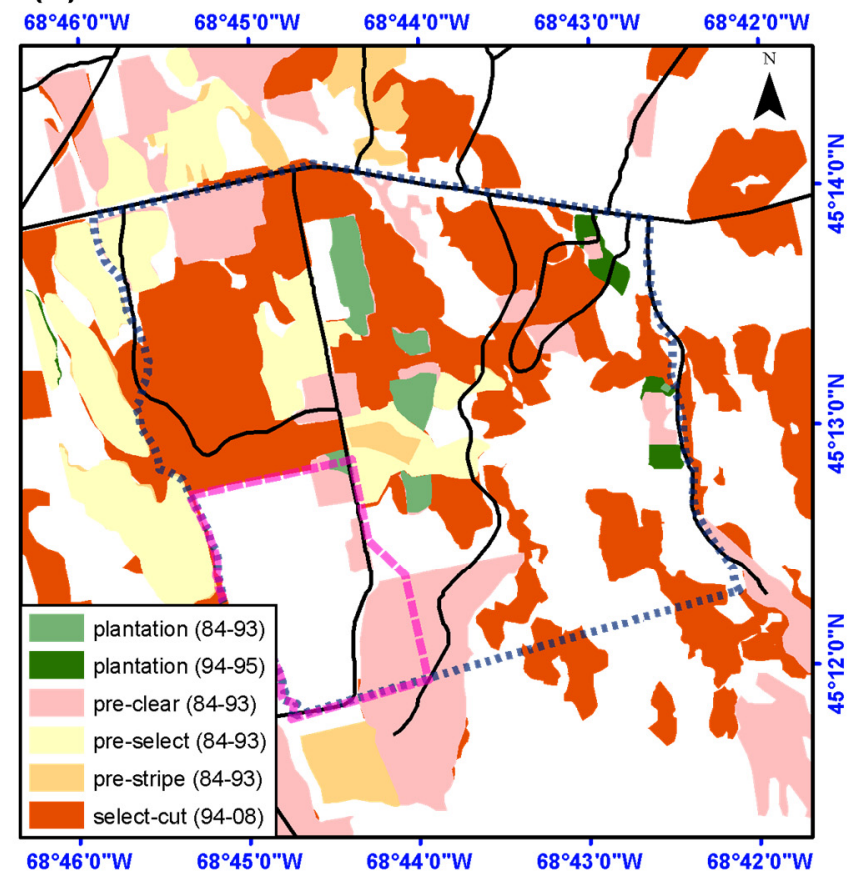

Figure 5. (a) Selected plots on AIRSAR image (10/07/1994, R: HH, G: HV, B: VV), and (b) Forest management map of the study site. Pink polygon is near-mature forest; dark blue polygon is the outline of the reserve area. Solid line polygons with labels (i.e., PLT89 = plantation in 1989; CC86 = clear-cut in 1986; STC92 = strip-cut in 1992; SHL08 = shelterwood harvest in 2008) are the plots selected for sensitivity analysis; S1 is the saturation point in a near-mature forest (biomass $>200 \mathrm{Mg} \cdot \mathrm{ha}^{-1}$ ); S2 is the maximum soil effect point in a non-forested area (biomass $<10 \mathrm{Mg} \cdot \mathrm{ha}^{-1}$ ). 


\subsection{Regression Model for Forest Biomass Mapping}

Forest biomass values are related to $\operatorname{SAR}$ backscatter $\left(\sigma_{p}^{o}\right)$ as:

$$
\mathrm{AGB}=\mathrm{e}^{\left(a+b \sigma_{p}^{\circ}\right)}
$$

where $\sigma_{p}^{o}$ represents the backscatter value (i.e., sigma naught) at different polarizations (i.e., HH, HV) and $a$ and $b$ are the exponential coefficients. To improve the fitting process, we estimated coefficients using a linear regression:

$$
y=a+b \sigma_{p}^{o}
$$

where $y=\ln$ (biomass) and $a$ and $b$ are the linear coefficients.

We assessed the regression models using leave-one-out cross-validation (LOOCV) performed with $\mathrm{R}$ (Version 2.14.2) [41]. The predicted values were regressed against the field-measured values to quantify the accuracy of the model using statistical indicators such as root mean square error from cross-validation $\left(R M S E_{C V}\right)$, relative error of $R M S E c v(R M S E c v \%)$, and coefficient of determination $\left(R^{2}\right)$. The LOOCV is an effective solution to evaluate the regression models with a small number of samples (i.e., <30) to test the model [42]. The general procedure of LOOCV is described as follows:

(1) Select observation $i$ to form a test set (i.e., $n$ independent observations $y_{1}, \ldots, y_{n}$ ) and fit the model using the remaining data. Then, compute the predicted residual for the omitted observation:

$$
e_{i}^{*}=y_{i}-\hat{y}_{i}
$$

(2) Repeat step 1 for $i=1, \ldots, n$.

(3) Compute the RMSE from $e_{1}^{*}, \ldots, e_{n}^{*}$, which is called RMSEcv.

The ratio of $R M S E c v$ to mean observed value is also calculated:

$$
R M S E c v(\%)=\frac{R M S E c v}{\bar{y}}
$$

where $\bar{y}$ is the mean biomass.

\section{Results}

\subsection{Sensitivity of SAR Backscatter to Incidence Angle}

The correction models and coefficients of determination derived from UAVSAR data for three polarizations are given in Table 2. Cosine models were applied to normalize backscatter at $\mathrm{HH}$ and HV polarization, and a linear model was used to normalize backscatter at VV polarization. A plot of SAR backscatter data as a function of incidence angle (Figure 6) illustrates the trend of SAR backscatter before and after the incidence angle based radiometric correction. Before correction, there are significant decreasing trends along the incidence angle for both AIRSAR (Figure 6a) and UAVSAR (Figure 6c). After incidence angle correction, the overall trends of backscatter along the incidence angle were mostly removed (Figure 6c,d). Although there is a slightly decreasing trend from $20^{\circ}-30^{\circ}$, the corrected sigma values stayed relatively stable $\left(<1 \mathrm{~dB}\right.$ variation) from $30^{\circ}-60^{\circ}$ in all three polarizations (i.e., $\mathrm{R}$ : $\mathrm{HH}$, G: HV, B: VV). 
Table 2. Correction model parameters and coefficients of determinant for three polarizations.

\begin{tabular}{|c|c|c|c|}
\hline Polarization & Correction Model & $\mathbf{n}$ & $\mathbf{R}^{2}$ \\
\hline $\mathrm{HH}$ & \multirow{2}{*}{$\sigma_{\text {corr }}^{o}=\sigma_{\text {raw }}^{o} \cdot\left(\cos \theta_{c} / \cos \theta_{\text {raw }}\right)^{n}$} & 1.5940 & 0.9733 \\
\hline $\mathrm{HV}$ & & 1.5250 & 0.9665 \\
\hline VV & $\sigma_{\text {corr }}^{o}=\sigma_{\text {raw }}^{o} \cdot\left(\theta_{\mathrm{c}} / \theta_{\text {raw }}\right)^{n}$ & -1.3293 & 0.9777 \\
\hline
\end{tabular}
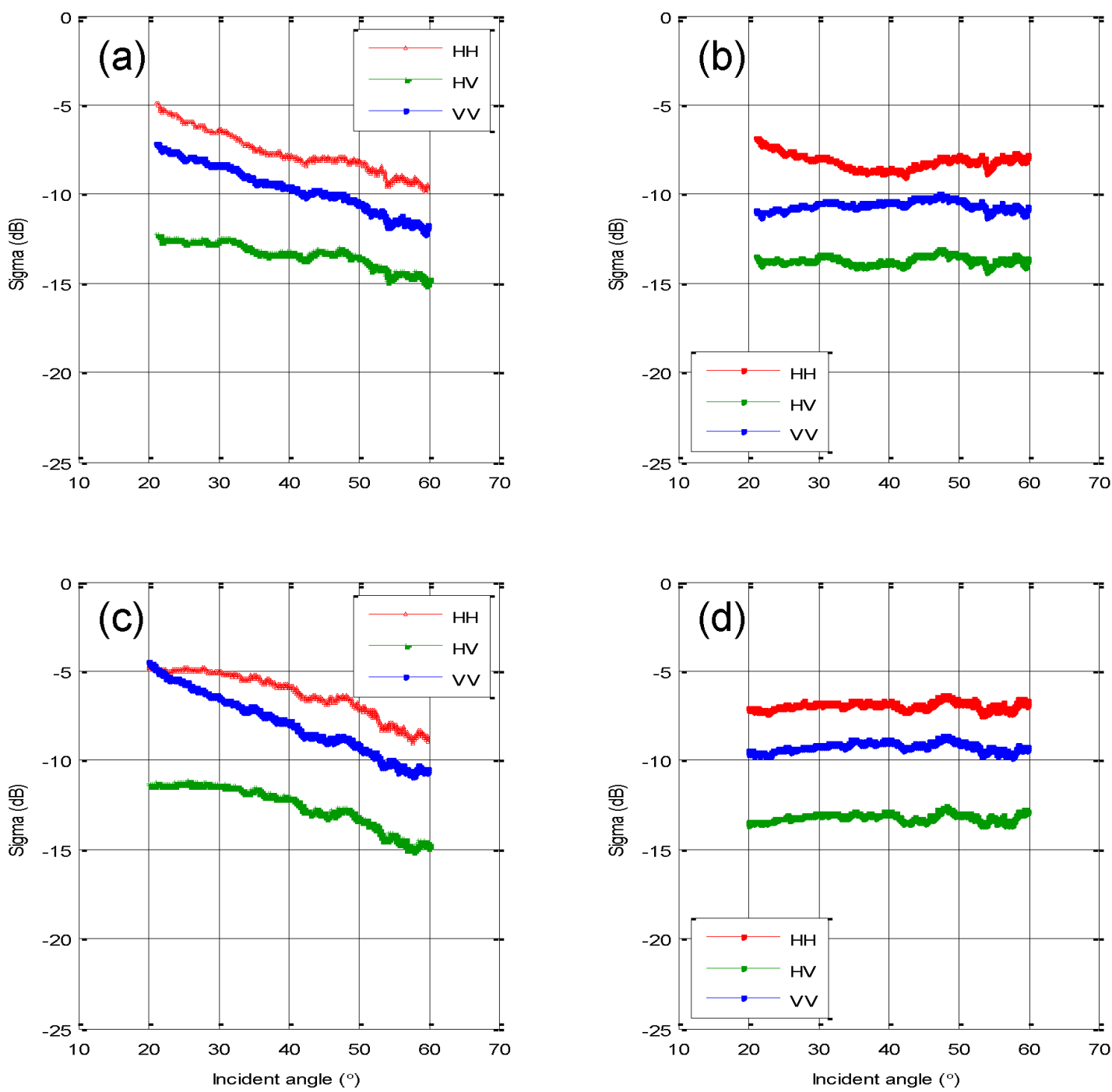

Figure 6. Mean backscatter in three polarizations (R: HH, G: HV, B: VV) as a function of incidence angle. AISSAR data acquired on 7 October 1994 before (a) and after incidence angle normalization (b); UAVSAR data acquired on 5 August 2009 before (c) and after incidence angle normalization $(\mathbf{d})$.

\subsection{Sensitivity of SAR Backscatter to Soil Moisture}

Two plots with field measurements taken in 2009 were selected to study the sensitivity of backscatter to soil moisture (Figure 7). Soil water fraction by volume (WFV) was collected at $5 \mathrm{~cm}$ depth from the Main Tower, Howland. The SAR backscatter was extracted from PALSAR data collected during the 2007-2010 growing seasons with incidence angle ranging from $37^{\circ}-40^{\circ}$. Scatter plots show an increase 
in backscatter with increasing soil moisture at $\mathrm{HH}$ polarization for the low biomass plot (Figure 7b). A correction of radiometric distortion due to different soil moisture conditions is possible.
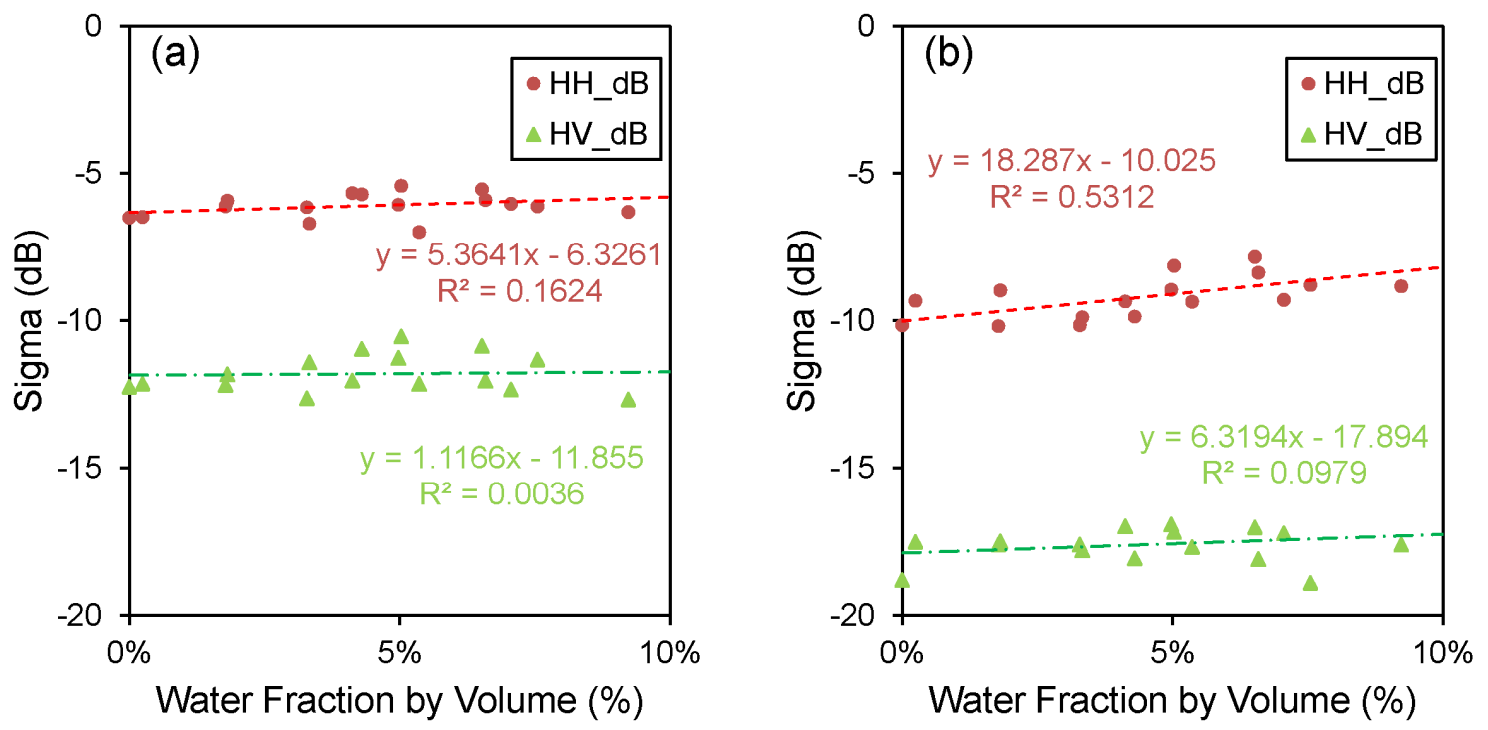

Figure 7. Mean backscatter (dB) plotted versus soil water fraction by volume (\%). (a) high biomass band, and (b) low biomass stand.

\subsection{Sensitivity of Normalized SAR Backscatter to Forest Biomass}

A two-step normalization was conducted on both airborne and spaceborne SAR data. First, spaceborne SIR-C data obtained on 13 April (PR12331) and 4 October (PR47494) 1994 were chosen to test the effectiveness of the proposed algorithm. Specifically, the SIR-C/XSAR data acquired in April were normalized to the data acquired in October. Changes in backscatter from the two SIR-C/XSAR scenes were illustrated for selected plots (Figure 8). The patch of forest near the flux tower was selected as the saturation point (S1), and the clear-cut patch of (CC86) with no canopy in 1994 was selected as the low biomass point (S2). The two selected scenes had similar sensor conditions (i.e., same looking direction and incidence angle). However, environmental conditions changed from April to October, including a temperature increase from $5.5^{\circ} \mathrm{C}-$ to $21.6{ }^{\circ} \mathrm{C}$, and an increase in surface soil moisture. The soil surface was very wet in April not only due to cumulative rainfall that fell three to seven days prior to the SAR acquisition, but also due to the presence of snow. While rainfall totals were higher in October two weeks prior to the SAR acquisitions ( $76 \mathrm{~mm} v s .50 .9 \mathrm{~mm}$, Table 1), melting snow and lower air temperature in April would have resulted in higher surface moisture. In fact, field crews in 1994 reported running water (small streams and ponds) at numerous locations in the forest. Finally, deciduous trees had not yet leafed out in April, while deciduous trees had retained their leaves in October, suggesting that sap flow (and thus stem dielectric properties) would have been lower in April than in October. 

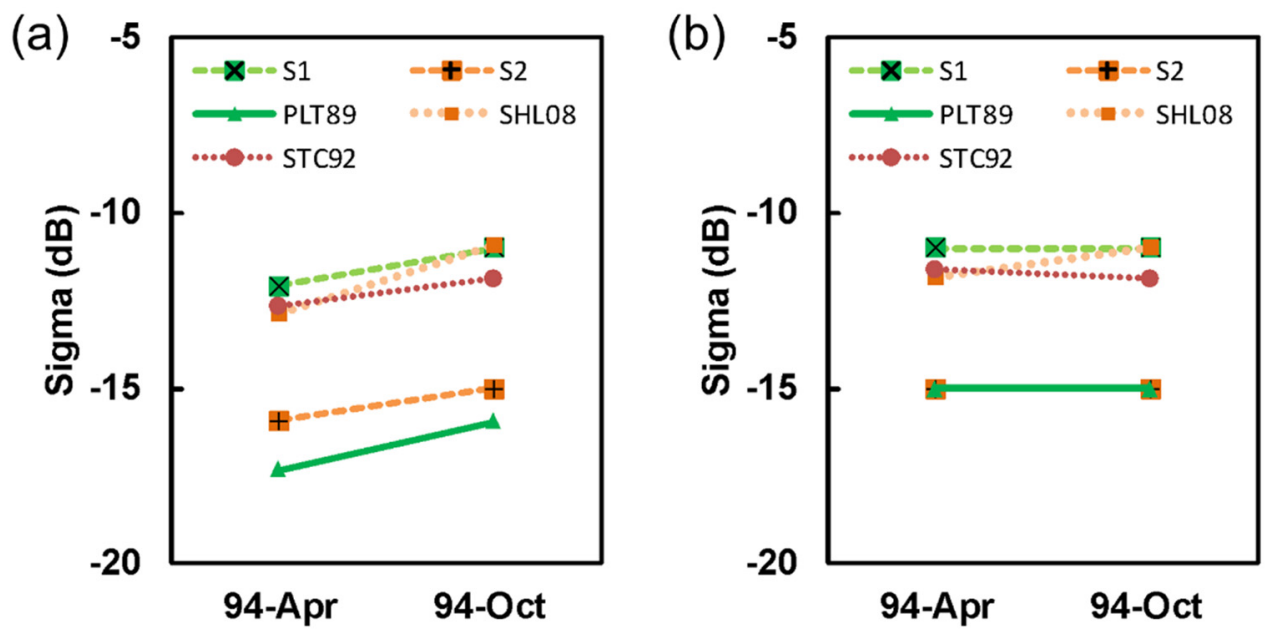

Figure 8. Changes in SAR backscatter (HV) from SIR-C/XSAR 1994 for selected plots; (a) before normalization, and (b) after normalization.
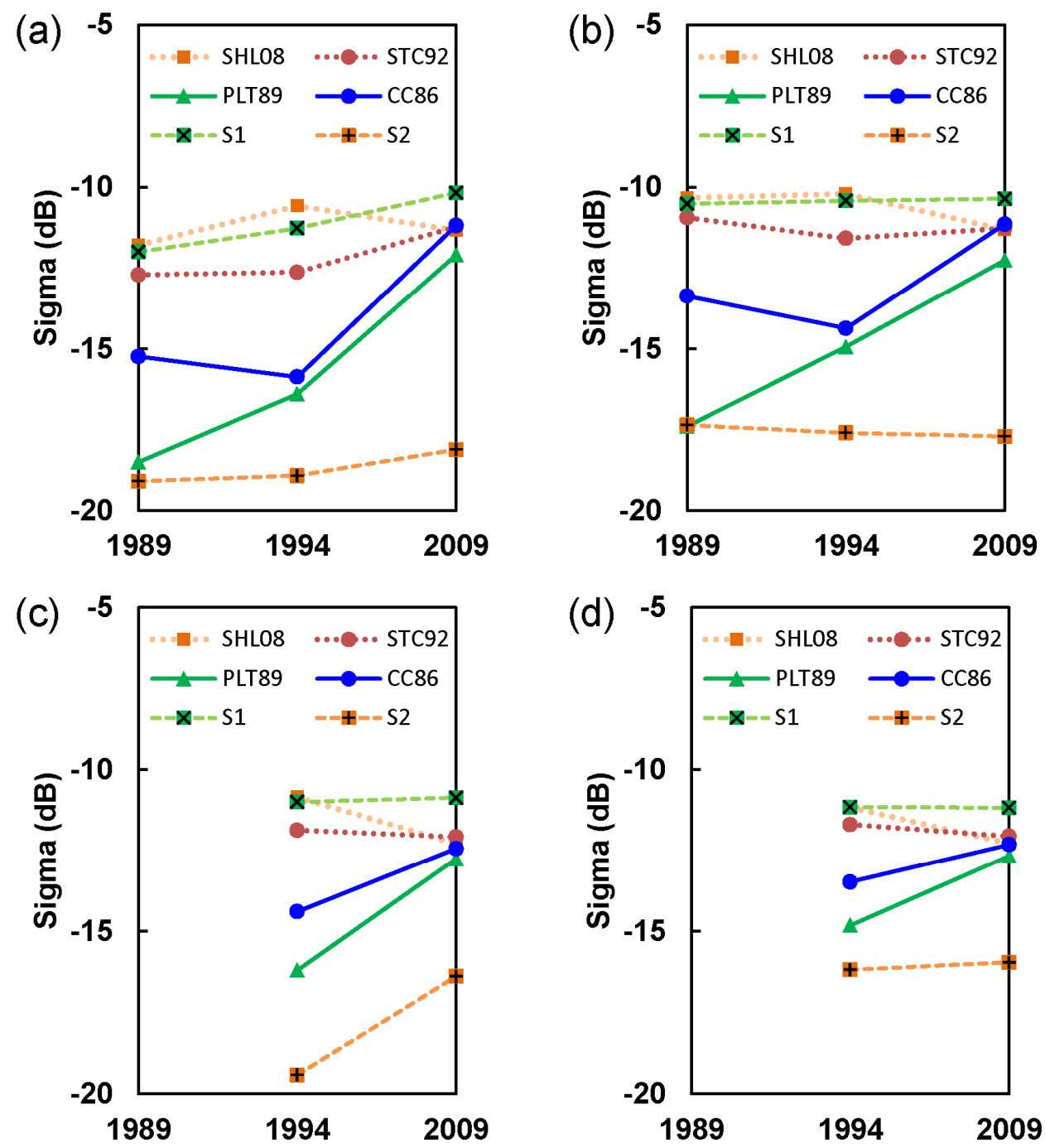

Figure 9. Changes in SAR backscatter (HV) from 1989-2009 at represented plots (a-d). $(\mathrm{a}, \mathrm{c})$ are values before and after normalization from the airborne data (AIRSAR 2 September 1989, 7 October 1994, and UAVSAR 5 August 2009), while (b,d) are values from the spaceborne data (SIR-C/XSAR 4 October 1994, and PALSAR 30 August 2009). 
Before the normalization, we saw an increasing trend of backscatter $(\sim 2 \mathrm{~dB})$ for all plots from April to October due to the changes in environmental conditions (a). After normalization, the trend was removed for most plots (i.e., S1, S2, and PLT89), and reduced for the select-cut plots (i.e., SHL08 and STC89) with subtle changes $(<1 \mathrm{~dB})$. The proposed two-step normalization algorithm successfully removed $50 \%-100 \%$ of the effects of environmental conditions on SAR backscatter. Therefore, the following section analyzes the sensitivity of normalized changes in backscatter to forest biomass over time using multi-source SAR data.

Changes in multi-sensor SAR backscatter over time were analyzed for selected plots. Airborne AIRSAR data from 1989 and 1994 were normalized to UAVSAR data in 2009. Spaceborne SIR-C data from October 1994 were normalized to PALSAR data from 2009. As expected, the change in biomass with time varies for different types of forest disturbance (Figure 9). Whole-stand disturbance (plantation after clear-cut) before the 1990s (PLT89) could be effectively detected by its backscatter signature. Plantation (PLT89) and natural recovery (CC86) are good examples to show post-disturbance recovery from clear-cut events before the 1990s. On the other hand, changes after partial-stand disturbance (i.e., shelterwood-harvest and strip-cut) could be detected by SAR signatures only under certain conditions. The strip-cut stand, which occurred in the 1990s (STC92), shows a relatively slow recovery rate, which is not sensitive to SAR signatures. However, the decrease of biomass from the shelterwood-cuts between 1994 and 2009 (e.g., SHL08) is detectable. For example, SHL08 means the first entry was in 1998 and the second entry was in 2008, when each time $\sim 1 / 3$ of the total biomass was removed. Previous model simulation [20] showed that when the radar looks perpendicular to the strip-cut direction, the radar signature does not change significantly. Meanwhile, the reason for the radar not being able to detect the regrowth may be that the radar signal after the strip-cut was still strong.

\subsection{Mapping Changes of Forest Biomass from SAR Backscatter}

Exponential regression models were derived from field measured biomass at the 1.0-ha plot-level and SAR backscatter data at HV polarization (Figure 10) with 95\% confidence intervals shown. Specifically, two models were developed: the PALSAR HV (a) model for spaceborne SAR data (SIR-C and PALSAR), and the UAVSAR HV (Figure 10b) model for airborne SAR data (AIRSAR and UAVSAR). Confidence intervals for both PALSR and UAVSAR are narrow at a lower range of biomass $\left(0-100 \mathrm{Mg} \cdot \mathrm{ha}^{-1}\right)$ but become wider at a higher range $\left(>100 \mathrm{Mg} \cdot \mathrm{ha}^{-1}\right)$. The models were applied to the corresponding SAR data, and biomass maps were generated at $100 \mathrm{~m}$ spatial resolution for the study site.

Changes of biomass (green to red color) from 1994-2009, derived from cross-image normalized multi-source SAR data at the HF site were mapped (Figure 11a, b), with the reclassified disturbance maps on the right (Figure 11c). A $100 \mathrm{~m}$ pixel size was used for biomass mapping. Most of the biomass changes derived from both spaceborne and airborne sensors are consistent with the forest disturbance patterns detected by the LTSS-VCT product. Specifically, both change maps show recent disturbance as well as regrowth after disturbance (highlighted by red and green colors in Figure 11c). In addition, results from airborne SAR systems (UAVSAR (2009 data) and AIRSAR (1994 data)) indicate more detailed changes in biomass than those from spaceborne systems (PALSAR (2009 data) and SIR-C (1994 data)). This is caused by the differences in the spatial resolution of SAR data. Airborne SAR data have a higher 
spatial resolution (i.e., $6 \mathrm{~m}$ for UAVSAR, and $10 \mathrm{~m}$ for AIRSAR) than spaceborne SAR data (i.e., $20 \mathrm{~m}$ for PALSAR, and $12.5 \mathrm{~m}$ for SIR-C/XSAR).
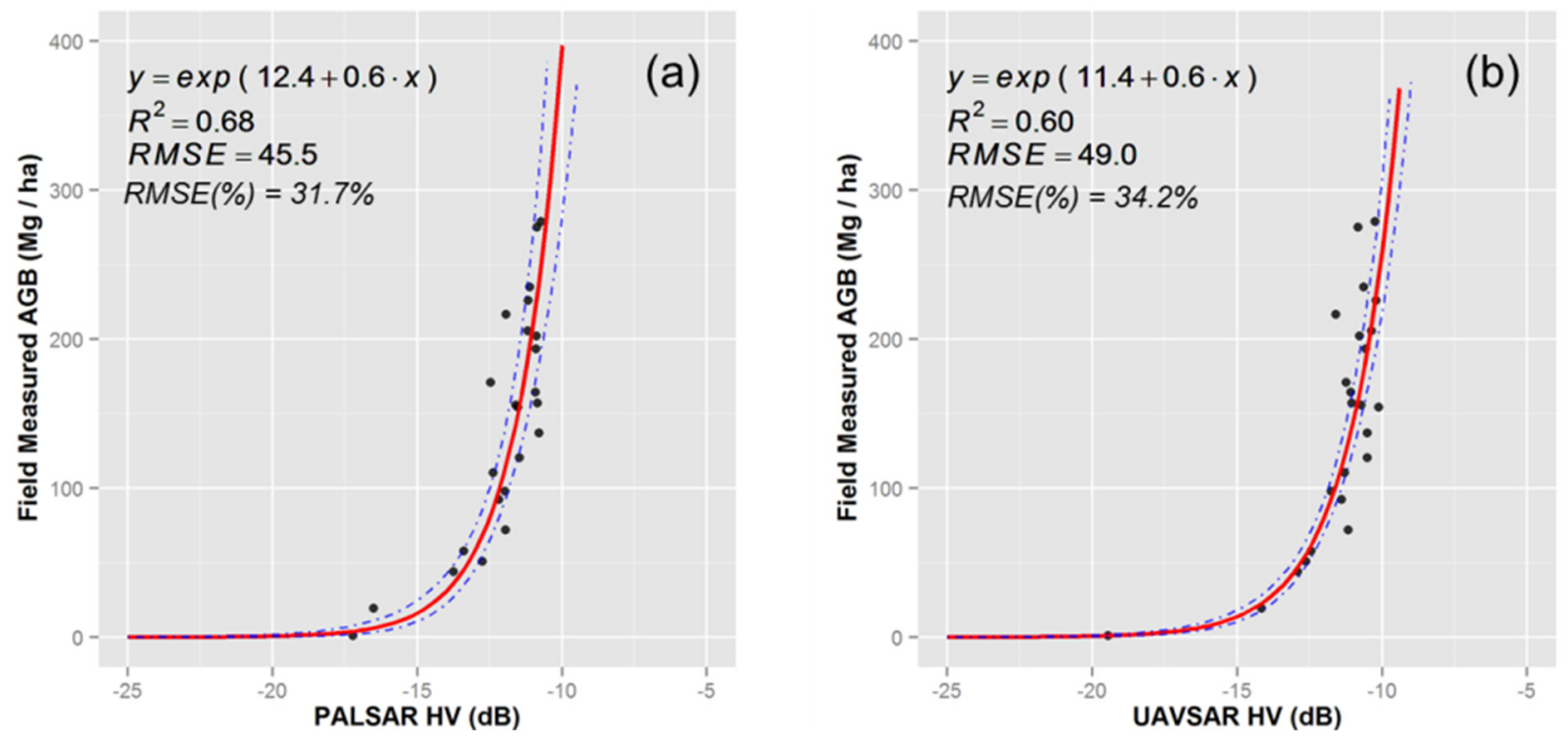

Figure 10. Field-measured biomass as an exponential function of SAR backscatter. (a) PALSAR HV, (b) UAVSAR HV; the Y-axis shows the field-measured biomass density at the 1.0 ha plot-level, and X-axis shows SAR backscatter at HV polarization in decibel $(\mathrm{dB})$; red solid line is the prediction curve; blue dashed lines indicate the $95 \%$ confidence intervals for the predictions.
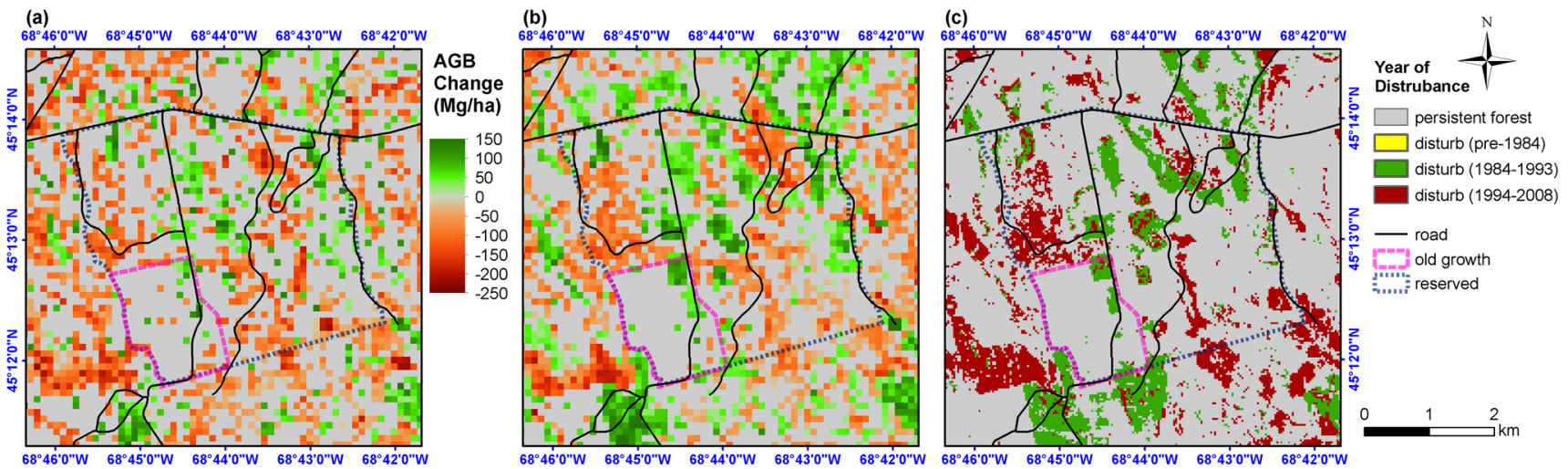

Figure 11. Change in biomass for HF site using cross-image normalized multi-source SAR data. (a) 2009PALSAR-1994SIR-C at $100 \mathrm{~m}$ spatial resolution, (b) 2009UAVSAR-1994AIRSAR at $100 \mathrm{~m}$ spatial resolution, and (c) reclassified year disturbance derived from LTSS-VCT product at $30 \mathrm{~m}$ spatial resolution. Different colors represent reclassified groups: prior to 1984 (yellow), between 1984 and 1993 (green), and between 1994 and 2008 (red), respectively.

\section{Discussion}

Our objectives were to investigate the influence of incidence angle (IA), soil moisture (SM), and changes in forest biomass on SAR backscatter. Knowledge from these analyses forms the basis for the cross-image normalization. Results from both spaceborne- and airborne-systems demonstrated that 
normalization ensured the derived biomass of regrowth forests was cross-calibrated, making the detection of biomass changes from multi-source SAR data possible. The forest biomass in the study area was mapped using multi-sensor SAR data from 1994 and 2009, and changes in biomass were derived for a 15-year period with both airborne and spaceborne systems.

Results from airborne systems indicated that the influence of IA on SAR backscatter could be reduced to less than $1 \mathrm{~dB}$ using an empirical model (Figure 6). We chose an empirical method for incidence angle correction because it is efficient and only needs basic sensor parameters (i.e., near range distance, instrument height, incident angle at near range and slant range resolution). Thus, this procedure was suitable for the study area, which has a relatively flat topography and limited information in terms of sensor parameters in the archived data (AIRSAR). However, a more advanced radiometric correction that integrates terrain variations [43] should be applied in regions with large terrain variation to improve the precision of the correction.

Second, the sensitivity of SAR backscatter to soil moisture was analyzed via spaceborne PALSAR data and in situ measurements from April 2007 to October 2010. A cross-image normalization procedure was used to reduce the influence of environmental and acquisition conditions among multi-source SAR data. This procedure successfully reduced the temporal changes in backscatter for SIR-C/XSAR data collected between April and October 1994 by 50\%-100\% (Figure 8). Assuming that surface roughness was the same in April and October, increased surface wetness would have increased direct backscattering from soil and double-bounce backscattering. More sap flow and higher temperatures in October increased the dielectric constant of the tree trunks, increasing direct backscatter from the trunk and the trunk-ground double bounce. A further application to multi-sensor SAR data indicated that the proposed procedure successfully reduced radiometric distortions due to different acquisition conditions (Figure 9). We chose near-mature forest stands and non-forested area because they met the requirements for high and low biomass in the conceptual diagram (Figure 4). Future work needs to incorporate physical-based models and develop according normalization algorithms.

In addition, the influence of incidence angle and soil moisture depends on the area and location of the study area. For instance, previous studies suggest that correction of the incidence angle effect is essential for a study area with a range of incidence angle greater than $10^{\circ}$ across the landscape [39]. The effects of soil moisture will become more important as a study area approaches national to continental scale because of the increasing spatial variation in soil moisture. However, current soil moisture products derived from interpolation of meteorological station data or available satellite observation have limited spatial and temporal resolution. For example, the Aqua Advanced Microwave Scanning Radiometer-EOS (AMSE-E) has a nominal spatial resolution of $25 \mathrm{~km}$ [23], which is beyond the scale of our study site. The relationship between SAR backscatter and soil moisture for the forested and non-forested areas is still under exploration because of limited observational as well as high-temporal SAR data.

Third, the ability to detect forest biomass reduction and regrowth using SAR backscatter also depends on numerous other factors such as the level of disturbance, model uncertainties, radar looking directions, forest structures, trunk dielectric properties, and tree species. Forest recovery from whole-stand disturbance ( $>50 \%$ removal), such as natural regrowth and plantation after clear-cut events, could effectively be detected by backscatter signatures. Depending on the magnitude of change and radar looking direction, the recovery from partial-stand disturbance (shelterwood harvest and strip-cut with $<50 \%$ removal) was not always captured by SAR signatures. Uncertainty in biomass estimation from 
single-date models will affect this ability. We were able to detect changes for pixels with changes greater than $100 \mathrm{Mg} \cdot \mathrm{ha}^{-1}$ or above $50 \%$ of $150 \mathrm{Mg} \cdot \mathrm{ha}^{-1}$, although with a $\sim 50 \mathrm{Mg} \cdot \mathrm{ha}^{-1}$ prediction error from the model. This is consistent with our analysis of selected plots (Figure 9), indicating that the level of disturbance has an influence on SAR detection ability. A previous study [13] had mentioned the effect of forest structure and tree species composition on the biomass estimation. The model developed for biomass mapping in this study did not take these effects into account because of a relatively simple species composition in the study area. However, we still recommend considering structure and species effects in areas with more complicated composition.

Lastly, previous studies have indicated that a combination of multiple observations could improve the accuracy of biomass estimation from SAR data because multiple images provide more samples and using them together could reduce the radar speckle noise [44,45]. For example, Zhang [44] indicated that models developed using multi-direction SAR backscatters (i.e., left and right look) achieved the best performance in estimating forest biomass. Englhart et al. [45] demonstrated that regression models developed from multiple observations with multiple frequencies such as SAR data from PALSAR (L-band) and TerraSAR-X (X-band) are more accurate than regression models developed from single observations. There is a trade-off between pixel size and the ability to detect disturbance. Therefore, for biomass estimation, the data were resampled to a $100 \mathrm{~m}$ resolution, and a mean value was calculated for each cell so that it was large enough to reduce the speckle noise in the SAR data used in this study. Airborne SAR data (i.e., UAVSAR and AIRSAR) with higher spatial resolution revealed more detail than spaceborne data (i.e., PALASAR and SIR-C) in terms of changes in forest biomass.

\section{Conclusions}

This study analyzed the sensitivities of multi-temporal and multi-sensor SAR signatures to forest biomass, and applied an exponential regression model for mapping changes in forest biomass over a 15-year period at medium spatial resolution $(100 \mathrm{~m})$ using multi-source spaceborne and airborne SAR data. Results from this study improved our knowledge about L-band SAR's capability to monitor forest ecosystem disturbance and post-disturbance recovery. Findings from this study indicate that the use of a correction model can reduce incidence angle effects on SAR backscatter to less than $1 \mathrm{~dB}$, and that cross-image normalization can reduce the effect of soil moisture on changes in backscatter to less than $50 \%$. Thus, the changes in forest biomass greater than $100 \mathrm{Mg} \cdot \mathrm{ha}^{-1}$ or above $50 \%$ of $150 \mathrm{Mg} \cdot \mathrm{ha}^{-1}$ are detectable using cross-normalized SAR data.

Several current and future spaceborne SAR systems will continue to provide data for these types of studies. The ALOS PALSAR-2 was launched in 2014 providing high resolution $(10 \mathrm{~m})$ and a 14-day repeat cycle to monitor forest carbon changes. The NASA-ISRO Synthetic Aperture Radar (NISAR) mission, which is designed to carry an L-band and S-band SAR to study hazard and global environmental change, is set to launch in 2020. Future soil moisture products with better spatial resolution $(3 \mathrm{~km})$ will be available from the Soil Moisture Active Passive (SMAP, launched in 2015) mission, which will improve biomass predictions from SAR data by reducing the effects of surface wetness. Findings from this study will provide calibration and validation methods as the foundation for improving the performance of current and future spaceborne systems. 


\section{Acknowledgments}

The authors would like to express thanks to UAVSAR team in Jet Propulsion Laboratory, NASA, and Alaska Satellite Facility for processing and providing UAVSAR data, and the archived SIR-C/XSAR and AIRSAR data. The original PALSAR data are provided by JAXA. Also, we would like to give special thanks to John Lee and Bryan Dail at University of Maine for coordinating in field campaign and local management maps, Chengquan Huang for acquisition and processing of LTSS-VCT disturbance product over the study area, Eric Kasischke and Bruce Cook for their conceptual advice and comments throughout the research. We are also greatly appreciative of the constructive comments from the anonymous reviewers.

Funding for this work was provided by NASA's Terrestrial Ecology Program (NNX09AG66G) and Carbon Monitoring System (NNX10AT74G). Google Earth® image (Figure 4).

\section{Author Contributions}

Wenli Huang, Guoqing Sun, Wenjian Ni, and Zhiyu Zhang designed the study and conducted the SAR data processing. Wenli Huang and Guoqing Sun analyzed and interpreted the result, and wrote the manuscript. Ralph Dubayah provided useful suggestions to data analyses, discussion and result interpretations. All the authors worked on the interpretation of results and manuscript revisions.

\section{Conflicts of Interest}

The authors declare no conflict of interest.

\section{References}

1. Goetz, S.; Dubayah, R. Advances in remote sensing technology and implications for measuring and monitoring forest carbon stocks and change. Carbon Manag. 2011, 2, 231-244.

2. Houghton, R.A.; Hall, F.; Goetz, S.J. Importance of biomass in the global carbon cycle. J. Geophys. Res.: Biogeosci. 2009, 114, G00E03.

3. Hall, F.G.; Bergen, K.; Blair, J.B.; Dubayah, R.; Houghton, R.; Hurtt, G.; Kellndorfer, J.; Lefsky, M.; Ranson, J.; Saatchi, S.; et al. Characterizing 3D vegetation structure from space: Mission requirements. Remote Sens. Environ. 2011, 115, 2753-2775.

4. Kasischke, E.S.; Melack, J.M.; Craig Dobson, M. The use of imaging radars for ecological applications - A review. Remote Sens. Environ. 1997, 59, 141-156.

5. Lu, D. The potential and challenge of remote sensing-based biomass estimation. Int. J. Remote Sens. 2006, 27, 1297-1328.

6. Santos, J.R.; Lacruz, M.S.P.; Araujo, L.S.; Keil, M. Savanna and tropical rainforest biomass estimation and spatialization using JERS-1 data. Int. J. Remote Sens. 2002, 23, 1217-1229.

7. Collins, J.N.; Hutley, L.B.; Williams, R.J.; Boggs, G.; Bell, D.; Bartolo, R. Estimating landscape-scale vegetation carbon stocks using airborne multi-frequency polarimetric synthetic aperture radar (SAR) in the savannahs of north australia. Int. J. Remote Sens. 2009, 30, 1141-1159. 
8. Mitchard, E.T.A.; Saatchi, S.S.; Woodhouse, I.H.; Nangendo, G.; Ribeiro, N.S.; Williams, M.; Ryan, C.M.; Lewis, S.L.; Feldpausch, T.R.; Meir, P. Using satellite radar backscatter to predict above-ground woody biomass: A consistent relationship across four different african landscapes. Geophys. Res. Lett. 2009, 36, L23401.

9. Ranson, K.J.; Sun, G. Mapping biomass of a northern forest using multifrequency SAR data. IEEE Trans. Geosci. Remote Sens. 1994, 32, 388-396.

10. Ranson, K.J.; Saatchi, S.; Guoqing, S. Boreal forest ecosystem characterization with SIR-C/XSAR. IEEE Trans. Geosci. Remote Sens. 1995, 33, 867-876.

11. Dobson, M.C.; Ulaby, F.T.; Pierce, L.E.; Sharik, T.L.; Bergen, K.M.; Kellndorfer, J.; Kendra, J.R.; Li, E.; Lin, Y.C.; Nashashibi, A.; et al. Estimation of forest biophysical characteristics in northern michigan with Sir-C/X-Sar. IEEE Trans. Geosci. Remote Sens. 1995, 33, 877-895.

12. Sandberg, G.; Ulander, L.M.H.; Fransson, J.E.S.; Holmgren, J.; le Toan, T. L- and P-band backscatter intensity for biomass retrieval in hemiboreal forest. Remote Sens. Environ. 2011, 115, 2874-2886.

13. Robinson, C.; Saatchi, S.; Neumann, M.; Gillespie, T. Impacts of spatial variability on aboveground biomass estimation from L-band radar in a temperate forest. Remote Sens. 2013, 5, 1001-1023.

14. Luckman, A.; Baker, J.; Kuplich, T.M.; Yanasse, C.D.C.F.; Frery, A.C. A study of the relationship between radar backscatter and regenerating tropical forest biomass for spaceborne SAR instruments. Remote Sens. Environ. 1997, 60, 1-13.

15. Balzter, H.; Skinner, L.; Luckman, A.; Brooke, R. Estimation of tree growth in a conifer plantation over 19 years from multi-satellite L-band SAR. Remote Sens. Environ. 2003, 84, 184-191.

16. Rowland, C.S.; Balzter, H.; Dawson, T.P.; Luckman, A.; Patenaude, G.; Skinner, L. Airborne SAR monitoring of tree growth in a coniferous plantation. Int. J. Remote Sens. 2008, 29, 3873-3889.

17. Santoro, M.; Fransson, J.E.S.; Eriksson, L.E.B.; Ulander, L.M.H. Clear-cut detection in swedish boreal forest using multi-temporal alos PALSAR backscatter data. IEEE J. Sel. Top. Appl. Earth Obs. Remote Sens. 2010, 3, 618-631.

18. Sun, G.; Simonett, D.S.; Strahler, A.H. A radar backscatter model for discontinuous coniferous forests. IEEE Trans. Geosci. Remote Sens. 1991, 29, 639-650.

19. Wang, Y.; Day, J.L.; Davis, F.W.; Melack, J.M. Modeling L-band radar backscatter of alaskan boreal forest. IEEE Trans. Geosci. Remote Sens. 1993, 31, 1146-1154.

20. Sun, G.; Ranson, K.J. Radar modelling of forest spatial patterns. Int. J. Remote Sens. 1998, 19, 1769-1791.

21. Harrell, P.A.; Kasischke, E.S.; Bourgeau-Chavez, L.L.; Haney, E.M.; Christensen, N.L., Jr. Evaluation of approaches to estimating aboveground biomass in southern pine forests using SIR-C data. Remote Sens. Environ. 1997, 59, 223-233.

22. Kasischke, E.S.; Tanase, M.A.; Bourgeau-Chavez, L.L.; Borr, M. Soil moisture limitations on monitoring boreal forest regrowth using spaceborne L-band SAR data. Remote Sens. Environ. 2011, $115,227-232$.

23. Lucas, R.; Armston, J.; Fairfax, R.; Fensham, R.; Accad, A.; Carreiras, J.; Kelley, J.; Bunting, P.; Clewley, D.; Bray, S.; et al. An evaluation of the ALOS PALSAR L-band backscatter-Above ground biomass relationship Queensland, Australia: Impacts of surface moisture condition and vegetation structure. IEEE J. Sel. Top. Appl. Earth Obs. Remote Sens. 2010, 3, 576-593. 
24. Way, J.; Paris, J.; Dobson, M.C.; McDonals, K.; Ulaby, F.T.; Weber, J.; Ustin, L.; Vanderbilt, V.C.; Kasischke, E.S. Diurnal change in trees as observed by optical and microwave sensors: The EOS synergism study. IEEE Trans. Geosci. Remote Sens. 1991, 29, 807-821.

25. Dobson, M.C.; Ulaby, F.T.; LeToan, T.; Beaudoin, A.; Kasischke, E.S.; Christensen, N. Dependence of radar backscatter on coniferous forest biomass. IEEE Trans.Geosci. Remote Sens. 1992, 30, 412-415.

26. Ranson, K.J.; Sun, G. An evaluation of AIRSAR and Sir-C/X-Sar images for mapping northern forest attributes in Maine, USA. Remote Sens. Environ. 1997, 59, 203-222.

27. Ranson, K.J.; Sun, G. Effects of environmental conditions on boreal forest classification and biomass estimates with SAR. IEEE Trans. Geosci. Remote Sens. 2000, 38, 1242-1252.

28. Imhoff, M.L. Radar backscatter and biomass saturation: Ramifications for global biomass inventory. IEEE Trans. Geosci. Remote Sens. 1995, 33, 511-518.

29. Zink, M.; Olivier, P.; Freeman, A. Cross-calibration between airborne SAR sensors. IEEE Trans. Geosci. Remote Sens. 1993, 31, 237-245.

30. Ustin, S.; Wessman, C.; Curtiss, B.; Kasischke, E.; Way, J.B.; Vanderbilt, V. Opportunities for using the EOS imaging spectrometers and synthetic aperture radar in ecological models. Ecology 1991, 72, 1934-1945.

31. Sandberg, G.; Ulander, L.M.H.; Wallerman, J.; Fransson, J.E.S. Measurements of forest biomass change using P-band synthetic aperture radar backscatter. IEEE Trans. Geosci. Remote Sens. 2014, $52,6047-6061$.

32. Huang, W.; Sun, G.; Dubayah, R.; Cook, B.D.; Montesano, P.M.; Ni, W.; Zhang, Z. Mapping biomass change after forest disturbance: Applying lidar footprint-derived models at key map scales. Remote Sens. Environ. 2013, 134, 319-332.

33. Jenkins, J.C.; Chojnacky, D.C.; Heath, L.S.; Birdsey, R.A. National-scale biomass estimators for United States tree species. For. Sci. 2003, 49, 12-35.

34. Huang, C.; Goward, S.N.; Masek, J.G.; Thomas, N.; Zhu, Z.; Vogelmann, J.E., An automated approach for reconstructing recent forest disturbance history using dense Landsat time series stacks. Remote Sens. Environ. 2010, 114, 183-198.

35. Urban, D. A Versatile Model to Simulate Forest Pattern: A User'S Guide to ZELIG Version 1.0; Environmental Sciences Department, The University of Virginia: Charlottesville, VI, USA, 1990.

36. Levine, E.R.; Knox, R.G.; Lawrence, W.T. Relationships between soil properties and vegetation at the northern experimental forest, Howland, Maine. Remote Sens. Environ. 1994, 47, 231-241.

37. Ranson, K.J.; Sun, G.; Knox, R.G.; Levine, E.R.; Weishampel, J.F.; Fifer, S.T. Northern forest ecosystem dynamics using coupled models and remote sensing. Remote Sens. Environ. 2001, 75, 291-302.

38. Ni, W.; Sun, G.; Guo, Z.; Zhang, Z.; He, Y.; Huang, W. Retrieval of forest biomass from alos PALSAR data using a lookup table method. IEEE J. Sel. Top. Appl. Earth Obs. Remote Sens. 2013, V6, 875-886.

39. Menges, C.; van Zyl, J.; Hill, G.; Ahmad, W. A procedure for the correction of the effect of variation in incidence angle on AIRSAR data. Int. J. Remote Sens. 2001, 22, 829-841.

40. Sun, G.; Ranson, K.J.; Kharuk, V.I. Radiometric slope correction for forest biomass estimation from sar data in the western Sayani Mountains, Siberia. Remote Sens. Environ. 2002, 79, 279-287. 
41. Kuhn, M. Building predictive models in R using the caret package. J. Stat. Softw. 2008, 28, 1-26.

42. Zhao, K.; Popescu, S. Lidar-based mapping of leaf area index and its use for validating globcarbon satellite LAI product in a temperate forest of the southern USA. Remote Sens. Environ. 2009, 113, $1628-1645$.

43. Small, D., Flattening gamma: Radiometric terrain correction for SAR imagery. IEEE Trans Geosci. Remote Sens. 2011, 49, 3081-3093.

44. Zhang, Z. Biomass Retrieval Based on Lidar and SAR Data. Ph.D. Dissertation, Beijing Normal University, Beijing, China, 2011. (In Chinese).

45. Englhart, S.; Keuck, V.; Siegert, F. Aboveground biomass retrieval in tropical forests-The potential of combined X- and L-band SAR data use. Remote Sens. Environ. 2011, 115, 1260-1271.

(C) 2015 by the authors; licensee MDPI, Basel, Switzerland. This article is an open access article distributed under the terms and conditions of the Creative Commons Attribution license (http://creativecommons.org/licenses/by/4.0/). 